
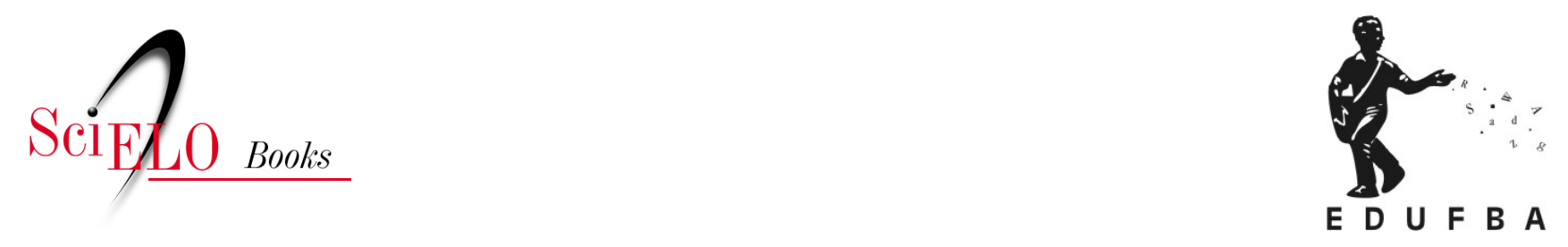

\title{
Interatividade e participação em contexto de convergência midiática
}

\author{
Maria Clara Aquino
}

\section{SciELO Books / SciELO Livros / SciELO Libros}

AQUINO, M. C. Interatividade e participação em contexto de convergência midiática. In: RIBEIRO, J.C., FALCÃO, T., and SILVA, T. orgs. Midias sociais: saberes e representações [online]. Salvador: EDUFBA, 2012, pp. 11-30. ISBN 978-85-232-1734-1. Availablefrom: doi: 10.7476/9788523217341.002. Also available in ePUB from:

http://books.scielo.org/id/hcmrr/epub/ribeiro-9788523217341.epub

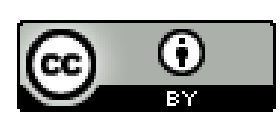

All the contents of this work, except where otherwise noted, is licensed under a Creative Commons Attribution 4.0 International license.

Todo o conteúdo deste trabalho, exceto quando houver ressalva, é publicado sob a licença Creative Commons Atribição 4.0. 


\title{
Interatividade e participação em contexto de convergência midiática
}

\author{
Maria Clara Aquino
}

\section{Introdução}

Ao tomar emprestados conhecimentos e teorias de outras áreas, como a Sociologia e a Computação, por exemplo, os estudos em cibercultura são ricos em terminologia. O campo é dotado de uma multiplicidade de termos e expressóes que, muitas vezes, desaparecem tão rápido quanto surgiram. Em outros casos, no entanto, permanecem, ainda que se tornem objeto de contestação, como a própria palavra que intitula a área. (FELINTO, 2011)

O título desse paper é constituído de termos recorrentes na cibercultura, pelo menos a partir dos anos 2000: interatividade, participação e convergência. O objetivo principal dessa reunião de palavraschave é tensionar um debate a partir de uma problematização que resulte de um cruzamento entre os conceitos. A motivação dessa tarefa surge da observação acerca de banalizações, equívocos ou descuidos quanto ao uso dos termos em determinados casos, tanto na imprensa quanto na academia. Esforços já foram realizados no intuito de esclarecer cada um dos conceitos, como no caso da interatividade (LÉVY, 1993; THOMPSON, 1998; LEMOS, 2002; PRIMO, 2007) e da convergência, ${ }^{1}$ de modo que não se pretende aqui detalhar cada um

\footnotetext{
Vide autores citados no primeiro parágrafo do próximo item.
} 
dos termos, embora um breve referencial teórico sobre cada um mereça ser explorado tendo em vista a consistência de um embasamento para a discussão que se pretende estabelecer.

O contexto de convergência midiática, no qual se propõe relacionar interatividade e participação, é caracterizado por transformações de caráter técnico, social e cultural, de modo que a própria noção de convergência deve ser pensada a partir desses três níveis. As reflexões são feitas com base nessas transformações, sempre impulsionadas por um movimento dialético entre esses níveis, buscando apontar questôes pertinentes à sociabilidade a partir de argumentações que transitam por diferentes vieses desse contexto de convergência.

\section{Convergência midiática: problematizando o conceito}

Em termos de mídia, Jenkins (2008) não foi o primeiro a falar em convergência, muito menos sua obra hoje mais comentada, Cultura da Convergência, é o primeiro trabalho sobre o tema. Por mais que recentemente venha recebendo destaque, tanto na imprensa como no meio acadêmico, por Cultura da Convergência, Jenkins, desde o início dos anos 1990, já apresentava estudos sobre as relações entre diferentes meios de comunicação e seus produtos midiáticos. ${ }^{2}$ Assim como ele, outros autores (MCLUHAN, 1964; POOL, 1990; SANTAELLA, 2003; CASTELLS, 2003; FRAGOSO, 2005, PELLANDA, 2003; MACHADO, 2003; NEGROPONTE, 1995; LÉVY, 1993) também já trabalhavam o assunto bem antes dessa exaltação ao termo que tem permeado a mídia e a academia.

Muitas definições sobre convergência se baseiam no componente tecnológico, de acordo com Grant e Wilkinson (2009), que apontam a tecnologia digital e as redes de computadores como o núcleo da

2 Em 1992, o autor publicou trabalhos sobre a cultura participativa, como, por exemplo: JENKINS, Henry (1992). Textual Poachers: Television Fans \& Participatory Culture. Studies in culture and communication. New York: Routledge. 
ideia de convergência midiática, ainda que, para eles, fatores organizacionais e sociais sejam de extrema importância na formação do conceito. No entanto, ainda que fundamental para sua definição, a tecnologia não é o único fator componente do conceito de convergência midiática, por isso o destaque para os níveis social e cultural, além do técnico, no início desse texto. Alerta-se para a necessidade de superação do caráter tecnicista do conceito, adotado por alguns autores como definidor do processo de convergência. No entanto, não negligencia-se tal caráter técnico; o que se promove é o seu posicionamento de maneira paralela aos caracteres social e cultural que também constituem o conceito.

Ainda que focados no cenário do jornalismo, pode-se fazer uma apropriação da argumentação de Salaverría e Avilés (2008), quando afirmam que se assiste a processos de convergência simultâneos nas esferas empresarial profissional e de conteúdos. Para os autores, sem dúvida, "todos estos fenómenos serían imposibles sin una condición instrumental previa que constituye la cuarta gran dimensión de esse fenómeno: la convergencia tecnológica"; ${ }^{3}$ e assim a dialética entre os níveis técnico, social e cultural já se torna mais transparente. Eles também percebem a atenção dada hoje ao conceito de convergência e recuperam os primeiros estudos sobre o mesmo, segundo eles, feitos há quase três décadas. Tais análises, explicam, colocavam o elemento tecnológico como o principal responsável pelo desencadeamento do fenômeno. Os autores citam Pool (1990) e Negroponte (1995) que, em sua opinião, concediam destaque ao fator tecnológico na composição do conceito. Há, porém, que se relevar as diferenças contextuais em que tais autores teceram suas análises, sem deixar de lado o fato de que, enquanto Negroponte (1995) conduzia um posicionamento fortemente tecnicista, Pool (1990) deixava transparecer, se não uma

3 Tradução da autora: “Todos esses fenômenos seriam impossíveis sem uma condição instrumental prévia que constitui a quarta grande dimensão desse fenômeno: a convergência tecnológica. 
preocupação, uma percepção acerca do papel do indivíduo nos processos comunicacionais a partir de sua relação com a tecnologia.

Um dos desafios impostos pelo termo convergência, de acordo Grant e Wilkinson (2009), é o de que vem sendo utilizado para se referir a fenômenos semelhantes ou relacionados a tecnologias de comunicação como, por exemplo, a transmissão de voz, dados e vídeo através de uma única conexão. A apropriação do termo é, no caso, absolutamente tecnicista, ainda que se possa pensar que a partir de tais possibilidades técnicas, alteraçôes sociais e culturais advenham de novas práticas decorrentes de novos usos. Eles explicam que o termo é utilizado para representar a ausência de limites entre diferentes tipos de mídia e, ao mesmo tempo em que há uma extensa lista de aplicações para o termo, afirmam que há uma série de fenômenos distintos que podem se encaixar no conceito. Não é, então, de se surpreender a ocorrência frequente de múltiplas e diversas apropriações, ora de caráter exclusivamente técnico, ora social, ora cultural, ou mesclas desses tipos, para designar um conceito de convergência, seja no âmbito 14 científico, seja na imprensa. Grant e Wilkinson (2009) consideram que o traço comum entre esses fenômenos, que consideram como convergência, está na substituição das transmissões analógicas pelas digitais, que permitem o armazenamento e a manipulação de qualquer tipo de mensagem a partir do momento em que ela é convertida em bits binários. Qualquer semelhança com o que Negroponte (1995) dizia nos anos 1990 seria mera coincidência?

Essa semelhança, no entanto, é amenizada quando um alerta feito pelos próprios autores, e que vem agregado ao background desse texto, destaca que a convergência vai além dessa questão técnica, pois representa um conjunto muito mais amplo de fenômenos, de modo que não se limita apenas ao fator tecnológico de conversão do analógico para o digital. Esses fenômenos, na verdade, seriam dimensões de uma conjuntura mais extensa que caracterizaria o processo de convergência. Essas dimensões, de acordo com Grant e 
Wilkinson (2009), seriam: a produção de conteúdo para múltiplos meios; o que eles chamam de copropriedade de dois ou mais meios por uma mesma empresa servindo ao mesmo mercado; a colaboração entre meios e profissionais, não necessariamente da mesma empresa; e a coordenação entre meios e profissionais de forma a compartilhar informações. Os autores citam essas dimensões no âmbito do jornalismo, e não abordam a participação dos consumidores de conteúdo no processo de convergência, como se pode perceber em outros autores que trabalham o conceito de convergência, mas, ainda assim, suas considerações ressaltam a necessidade de se avançar a reflexão sobre o conceito para além de um entendimento unicamente técnico do processo. A necessidade de se repensar e problematizar as expressões "interatividade" e "participação" decorrem dessa busca pelo entendimento de um conceito de convergência, que demanda uma diferenciação entre os termos, na medida em que também se permite compartimentar em função desses níveis técnicos, social e cultural.

Utilizando a teoria dos meios, Jensen (2010) reflete sobre a convergência a partir da relação entre a materialidade e a ação dos indivíduos. Para o autor, essa teoria é a tradição de pesquisa que confere maior sustentação às condições materiais da comunicação humana e é a partir dela que ele propõe a divisão dos meios materiais em três graus. Os meios de primeiro grau, para Jensen (2010), de acordo com uma perspectiva histórica e com a teoria da comunicação, são considerados como meios de comunicação os corpos dos seres humanos e determinados utensílios e instrumentos.

Em si, o corpo humano é uma condição material de comunicação necessária e suficiente; nossos corpos se tornam meios de comunicação produtivos e receptivos através da socialização e da aculturação. Em comparação, as ferramentas - utensílios de escrita ou instrumentos musicais - não são necessários nem suficientes, mas estendem, de maneira significativa, o corpo 
humano e suas capacidades comunicativas. ${ }^{4}$ (JENSEN, 2010, p. 66, tradução nossa)

Jensen (2010) diz que meios de primeiro grau externam mundos atuais e possíveis, de modo que habilitam as pessoas a se comunicarem umas com as outras sobre esses mundos para propósitos reflexivos e instrumentais.

Como meios de segundo grau, Jensen (2010) considera os meios de massa como sendo os livros impressos, os jornais, os filmes, o rádio e a televisão, ou seja, todas as formas de instituições midiáticas e práticas comunicacionais baseadas no modelo um-todos. $\mathrm{O}$ autor toma como base a expressão "meios de massa”, utilizada por Walter Benjamin nos seus termos de reprodução e disseminação técnica, especificamente no campo das artes, porém com implicações no campo das comunicações. Jensen (2010) explica que essas características foram, em primeiro lugar, reproduzidas, armazenadas e apresentadas em um conteúdo específico através de um modelo de um-para-um. Em segundo lugar, os meios de segundo grau, afirma o autor, estenderam radicalmente o potencial de disseminação do acesso à informação através do tempo e do espaço, independente da presença e do número de participantes.

É nos meios de terceiro grau que Jensen (2010) fala sobre a tecnologia digital e define essa categoria como metatecnologia. Para ele, o computador digital reproduz e promove uma recombinação de meios anteriores a ele em uma única plataforma material, utilizando a expressão metatecnologia a partir de Kay e Goldberg (1999/1977), que denominaram o computador de metameio. Reunindo textos, imagens e sons, Jensen (2010) explica que o meio digital se origina dos meios de massa, reunindo outras funcionalidades, como a interação face a

4 "In itself, the human body is a necessary and sufficient material condition of communication; our bodies become productive and receptive media of communication through socialization and acculturation. In comparison, tools - writing utensils or musical instruments - are neither necessary nor sufficient, but extend the human body and its communicative capacities in significant ways ". 
face, as narrativas, os debates e os games. Além disso, prossegue, o meio digital integra os diferentes modelos de comunicação: uma-para-um, uma-para-muitos e muitos-para-muitos. Para ele, o principal exemplo de que o meio digital incorpora o terceiro grau dos meios materiais é o computador pessoal em rede, ou seja, a internet, e ele ainda cita os celulares, a portabilidade e a mobilidade das conexões. Assim, Jensen (2010, p. 70) afirma que "with meta-technologies, communication has come full circle to the sort of interactive and multimodal forms of interchange that characterize face-to-face settings". ${ }^{5}$

O que Jensen (2010) tenta elucidar com sua classificação em três diferentes graus de materialização dos meios é que práticas diversas decorrem desses níveis de materialidade. Um meio material, explica, suporta práticas comunicativas diversas, assim como algumas práticas circulam de maneira adequada por vários meios; outras práticas são retomadas quando novas plataformas comunicacionais são incorporadas, quando surgem novos dispositivos tecnológicos, como, por exemplo, através das trocas de mensagens de texto por meio de telefones celulares. Ao contrário do que se pode inferir inicialmente, sua argumentação não condiz com a ideia de que os computadores e a internet caracterizariam o ideal de convergência pelo único e simples fato de reunirem todos os tipos de comunicação anteriormente existentes. Ainda que o ambiente digital seja propício para a reunião de diversos níveis de materialidade, Jensen (2010) toma como premissa o fato de que são as interações e as práticas comunicativas que caracterizam os intercâmbios comunicacionais responsáveis pelos processos de convergência e, nesse caso, a reflexão sobre tais processos requer a qualificação de questôes referentes à interatividade e à participação, diretamente relacionadas com os níveis social e cultural do conceito, além do nível técnico, evidentemente.

5 Tradução nossa: "Com as metatecnologias, a comunicação tem um círculo completo com os tipos interativos e multimodais que caracterizam as configuraçôes face a face”. 
No presente ambiente digital, apresenta-se um caso especial de um questionamento geral, subjacente à teoria dos meios sobre como potências materiais se tornam meios reais. Jensen (2010) resgata o conceito de "affordances" de James J. Gibson (1979), noção que, para Jensen (2010), ronda aspectos sociais e culturais dos meios de comunicação. Jensen (2010, p. 74) explica que "Suportes são, por um lado, as propriedades da natureza que as pessoas se referem e delas dependem, por outro lado, tais propriedades só se manifestam em relação a determinados organismos". ${ }^{6}$ No caso das interações humanas, prossegue o autor, existem diferenças marcantes entre os objetos encontrados com os usos que são dados a esses objetos, e os objetos que são produzidos, que apresentam usos que são desenvolvidos em sequências mais ou menos complexas e colaborativas. É comum a apropriação de determinados objetos utilizados para a comunicação tendo em vista uma espécie de adaptação para determinados tipos de situações comunicacionais, e, no caso da comunicação digital, essas práticas são frequentes.

Dessa forma, o entendimento desses suportes remete ao uso que lhes é dado. No caso dos meios de comunicação, segundo Jensen (2010, p. 75), "Os suportes dos meios são ao mesmo tempo gerais e programáveis". ${ }^{7}$ No entanto, o autor diz que há uma dificuldade em se aplicar o conceito de Gibson de forma consciente e explícita, já que haveria uma inconsistência no momento da verificação do mesmo. Jensen (2010) cita Norman (1990), que encara o conceito de Gibson como o aspecto de design de determinado objeto, sugerindo que este deva ser utilizado além de suas características atuais, e isso se percebe em diversas ferramentas de cunho social presentes na web, frequentemente apropriadas por seus usuários para finalidades

6 "Affordances are, on the one hand, properties of nature that humans refer to and depend on; on the other hand, such properties only manifest themselves relative to particular organisms". (Tradução nossa)

7 "The affordances of media are both general and programmable". (Tradução nossa) 
diferentes das inicialmente pensadas por seus idealizadores. Assim, o entendimento de Norman engloba não só a maneira como um objeto pode ser usado, como também suas propriedades atuais. No caso dos meios de comunicação, e mais propriamente no cenário dos meios digitais, o entendimento desse conceito de suporte se dá no contexto dos diversos usos que podem ser realizados e hoje são dados através da apropriação feita por diferentes indivíduos inseridos em variados contextos comunicacionais, bem como participantes de diversificados processos de comunicação, de maneira que os suportes materiais podem e são muitas vezes utilizados além de suas características atuais. Essas apropriações podem ser realizadas com objetivos que resultam em diferentes níveis de interatividade e/ou participação, de forma que a materialidade relacionada com a designação dada pelo indivíduo a determinado suporte ou meio interfere na definição do caráter que reveste o conceito de convergência.

Ao contrário de Norman, Gibson entende o suporte como uma possibilidade de ação capaz de ser realizada em um determinado ambiente, no qual o indivíduo se encontra naquele momento, porém, essa possibilidade independe da capacidade do indivíduo de percebêla. Jensen (2010) aponta que este fenômeno de fazer sem saber que se está fazendo tem sido referenciado na teoria social e cultural como conhecimento tácito, de modo que são ações e práticas que permitem aos indivíduos seguirem adiante. No caso dos meios de comunicação, o questionamento que Jensen (2010) faz a partir do conceito de Gibson é de como e por que alguns suportes materiais, e não outros, emergem como meios.

A partir disso, Jensen (2010) busca explicar o termo "emergência”, que, segundo ele, refere-se a um processo cujo estado final é imprevisível. O autor cita o ciberespaço de William Gibson como um espaço através do qual a história dos meios se utiliza para mostrar como os usos sociais de uma tecnologia se modificaram muito ao longo do tempo ou mudaram completamente de rumo. Além disso, 
o autor afirma que as próprias mídias são capazes de reconfigurar as condições de comunicação, ou seja, que diferentes mídias suportam diferentes tipos de modificação. No caso dos meios digitais, afirma o autor, os indivíduos podem alterar não só arquivos individuais, mas também um sistema inteiro de comunicação, sua forma e seu conteúdo. Logo, ao se tratar aqui do tensionamento entre interatividade e participação, nesse sentido, vai-se além da questão do conteúdo, já que, ao interferir no formato, extrapola-se os níveis de interatividade de maneira que o modelo de comunicação sofre impactos que reconfiguram a atuação de seus componentes não só na construção do conteúdo do processo comunicacional, mas também na constituição do próprio instrumento de comunicação que possibilita a produção do conteúdo.

A presente estrutura midiática digital demonstra o quanto a internet e a web se desenvolveram ao longo dos anos, desde as primeiras formas de comunicação mediada por computador, e o quanto se desviaram de seus propósitos iniciais, direcionando-se para a sociabilidade e para o estabelecimento de processos de convergência midiática. Resultado de apropriações e usos diversos, a comunicação estabelecida via rede se expandiu atingindo os demais meios de comunicação, estabelecendo, além de novos modelos comunicacionais, novas práticas e formatos midiáticos, obrigando a reflexão sobre questôes materiais e sociais que envolvem os processos comunicacionais que se desenvolvem através dos meios digitais e que promovem o desenvolvimento de uma cultura marcada pelo uso de novos tipos de ferramentas de comunicação.

Diante de tais alterações, Jensen (2010) reflete sobre essa questão do suporte falando sobre a interação diária dos usuários de internet, argumentando que a comunicação em rede deve questionar não só o que a mídia faz com as pessoas, mas também o que as pessoas fazem com a mídia. O que interfere hoje nesse processo e que produz um impacto direto no conceito de convergência midiática refere-se ao 
grau de interatividade e/ou participação dos indivíduos nos processos comunicacionais estabelecidos nesse contexto de convergência. Se antes as tecnologias de comunicação serviam apenas para distribuição de conteúdos midiáticos, hoje servem também para produção e compartilhamento de conteúdo. Dessa forma, provoca-se a reflexão sobre o conceito de convergência midiática, na medida em que essas características oscilam em função da materialidade dos suportes, questão que se encontra no nível técnico do conceito de convergência, e das apropriações realizadas pelos indivíduos no uso cotidiano das tecnologias de comunicação, temática que engloba os níveis sociais e culturais do fenômeno.

\section{Interatividade e participação em contexto de convergência midiática}

Um dos fatores que difere a internet dos demais meios de comunicação é a rapidez de seu alcance. A velocidade com que a internet vem se difundindo nas últimas três décadas não pode ser comparada com a velocidade de difusão de qualquer outro meio de comunicação, atesta Cardoso (2007), que recupera um questionamento de Castells quanto ao momento dessa difusão em alta velocidade. A resposta que Cardoso (2007) fornece à Castells divide-se entre razões de caráter tecnológico, como a popularização do computador e de outros aparelhos informáticos e comunicacionais, a facilidade de uso da web e o incentivo ao uso da internet no trabalho e na educação; e razões de caráter histórico, como uma realidade que atende à necessidade fundamental de uma sociedade com fortes raízes na evolução social, que se realiza através de uma ferramenta como a internet.

Ao mesmo tempo em que usam, as pessoas dessa sociedade se apropriam e modificam essa tecnologia, possibilidade decorrente do caráter aberto do modelo de tal tecnologia e ausente em outras tecnologias anteriores, como a televisão, o telefone e o rádio, por exemplo. 
Por isso a necessidade que esse trabalho levanta de se pensar transformações sociais, culturais e técnicas, numa época fortemente marcada pelo uso da internet para diversos tipos de atividades políticas, sociais e econômicas.

A cultura da convergência pode ser entendida como um estágio de comunicação no qual muitas pessoas participam da formação de universos de pensamento direcionados em um mesmo sentido. Para desenvolver-se nesse sentido, a convergência precisa da interação das pessoas, realizada através das mídias. Esta interação, por sua vez, depende do interesse criado pelos objetos que participam desta cultura, que pode ser iniciado através dos elementos estéticos destes. Em todos os estágios de comunicação desenvolvidos até a convergência, a interação, nos seus diversos níveis, mostra-se fundamental para a formação desta cultura em emergência. (FACCION, 2010)

Faccion (2010) é aqui citada por destacar a interação como elemento fundamental do conceito de convergência, ao mesmo tempo em que vincula a ocorrência dessa interação à questão da conexão. A autora discorre sobre o conceito de convergência a partir de Jenkins (2008), afirmando que a convergência teria um caráter fundamental de interação, dependendo, por um lado, da competência tecnológica do que chama de "novas mídias", responsáveis pela abertura de "caminhos de interatividade" e, por outro, estabelecendo "dois parâmetros de avaliação: a capacidade dos objetos de incitar a interação e o interesse da sociedade em interagir". (FACCION, 2010) A partir dessas afirmações, Faccion (2010) elabora um entendimento de convergência que avança além de um entendimento meramente tecnológico; sua argumentação estrutura-se sob a premissa de que a convergência se dá não apenas em função da tecnologia, mas também por "processos de interação possibilitados e encorajados na comunicação", de forma que o uso e a apropriação de tecnologias e conteúdos midiáti- 
cos pelos indivíduos seja um fator determinante na efetivação de um processo de convergência midiática.

A convergência pode ser entendida como um estado de comunicação alcançado após o envolvimento de diversas pessoas através do uso das mídias. Esse estado de comunicação pressupõe a criação de múltiplas manifestações que acrescentam pensamentos, interpretaçôes e reapresentações de um objeto inicial, capaz de atrair o interesse de muitas pessoas. (FACCION, 2010)

A abordagem desenvolvida por Faccion (2010) toma como ponto de partida a inserção das "novas mídias" dentro do cenário da comunicação, de forma que o uso e a apropriação dessas novas mídias pelos indivíduos colaborem para a concretização de um processo de convergência. Tal postulado vai ao encontro do que Dizard Jr. (2000, p. 40-41) discorre sobre esse tema. Para o autor, "a nova mídia não é apenas uma extensão linear da antiga"; a diferença consiste no fato de que ela, através da internet e de outros canais, expande a quantidade de recursos disponíveis para os consumidores; "em particular, a nova mídia está começando a prover conexões interativas entre o consumidor e o provedor de informação". Essas conexões permitem a interatividade entre produtores e consumidores de informação, segundo o autor, fazendo com que os consumidores possam escolher quando e como querem receber o conteúdo midiático. Assim, a origem do conceito de convergência midiática, no âmbito da internet, está enraizada nessa característica do meio que permite a conexão entre os indivíduos, bem como entre as informações disponíveis on-line. É a interatividade proporcionada pela conectividade do meio que justifica o caráter social do entendimento sobre convergência midiática adotado aqui.

Em um texto intitulado $O$ que aconteceu antes do YouTube, Jenkins (2009, p. 144) afirma que muito do que já foi escrito sobre o YouTube sugere que algumas tecnologias possibilitaram o surgimento de "cultu- 
ras participativas", porém, acredita mesmo é no contrário: "o surgimento das culturas participativas de todas as espécies ao longo das últimas décadas estabeleceu o caminho para a assimilação pioneira, rápida adoção e usos diversos dessas plataformas.” O que Jenkins (2009, p. 145) na verdade tenta mostrar é que antes da digitalização da comunicação já havia um "longo histórico de produção de mídia" e que plataformas como o YouTube não foram o ponto de partida dessas produções. Ainda que mesmo sem a mistura de linguagens, os indivíduos sempre produziram e buscaram conteúdo, de uma forma ou de outra. $\mathrm{O}$ que de novo surgiu não foram as práticas, mas sim as maneiras, os suportes através dos quais passaram a ser realizadas. O caso do YouTube serve como ilustração desse raciocínio:

Se o YouTube parece ter aparecido da noite para o dia, é porque já havia uma miríade de grupos esperando por algo como o YouTube; eles já tinham suas comunidades de prática que incentivavam a produção de mídia DIY, já haviam criado seus gêneros de vídeos e construído redes sociais por meio das quais tais vídeos podiam trafegar. O YouTube pode representar o epicentro da cultura participativa atual, mas não representa o ponto de origem para qualquer das práticas culturais associadas a ele. (JENKINS, 2009, p. 145)

A internet, a web e as tecnologias digitais de comunicação, dessa forma, foram responsáveis por potencializar práticas anteriormente existentes, facilitando atividades e contribuindo para alterações nos comportamentos dos indivíduos, mas não foram pioneiras em misturar elementos e linguagens de comunicação. Tais misturas iniciaram antes da configuração desse presente cenário digital, e o que mudou, e vem mudando, são os comportamentos dos indivíduos em torno dos conteúdos midiáticos. Por isso a crítica inicial que esse texto faz à exaltação excessiva e à apropriação, muitas vezes equivocada, da expressão "convergência midiática" e, a partir disso, propõe o tensionamento 
entre a interatividade e a participação num contexto de convergência, lucidamente delimitado.

É importante verificar como, no início dessas misturas, os comportamentos dos indivíduos foram se modificando. Quando Santaella (2003) afirma que, nos idos dos anos 1980, os indivíduos começaram a abandonar a "inércia da recepção", em função do surgimento de dispositivos como o controle remoto e o videocassete, que ampliaram as possibilidades de escolha dos indivíduos, é válido questionar como se deu esse abandono. $\mathrm{O}$ público começou a perceber a oferta de mais opçôes e passou a usar o controle remoto para fazer suas escolhas? Compraram pacotes de TV a cabo, videocassetes, personalizaram fitas cassete para escutarem em seus walkmans? Como se deu tal desprendimento?

A diferenciação que Jenkins (2008) faz entre os termos participação e interatividade é útil para se entender como se deu esse abandono, a evolução de uma postura passiva para outra mais ativa, pois gera um raciocínio sobre as mudanças ocorridas desde as primeiras misturas entre linguagens até o contexto atual, dito convergente. Para Jenkins (2008, p. 182), a interatividade é o "modo como as novas tecnologias foram planejadas para responder ao feedback do consumidor", assim que podem existir diferentes níveis de interatividade em função de cada tecnologia de comunicação. Já a participação é "moldada pelos protocolos culturais e sociais", (JENKINS, 2008, p. 183) mais ilimitada que a interatividade e controlada mais pelos consumidores dos produtos midiáticos que por seus produtores. Diante dessa diferenciação, poderia-se dizer que desde as primeiras misturas entre linguagens, que, como aponta Santaella (2003), se iniciaram em meados da década de 1980, o abandono da inércia da recepção foi abrindo o caminho para um cenário midiático mais interativo, em diferentes níveis, para, a partir do fim dos anos 1990, além 
de interativo, tornar-se mais participativo. ${ }^{8}$ No caso da televisão, por exemplo, Chagas (2010) atribui o anseio do telespectador por participação à busca de outros meios onde possa atuar de maneira mais ativa, e afirma que foi na internet que esse telespectador "encontrou espaço para 'falar', trocar informaçōes e produzir conteúdo".

Em termos de comportamento do telespectador, Murray (2003) credita alterações do mesmo aos processos de digitalização da informação, passando de atividades sequenciais para atividades simultâneas. Se antes o telespectador assistia ao conteúdo televisivo para depois interagir, hoje realiza as duas açôes ao mesmo tempo. Chagas (2010) afirma que, no Brasil, "mudanças no comportamento do telespectador e das produções já são identificadas, muito em função da popularização da Internet e do anseio por interagir e fazer parte da produção de conteúdo da TV". A autora recorre a Jenkins, explicando que, para ele, "esta nova 'prática interligada em rede' de consumir produtos televisivos, estando conectado à web, configura os modos de consumo e produção dos produtos televisivos". Ela diz que não se trata de assistir televisão pelo computador, mas sim no aparelho de televisão, comentando o conteúdo nas redes sociais on-line. Acompanhar o programa não é suficiente, ela explica; o telespectador, também internauta, quer compartilhar sua opinião sobre a programação, e o registro dessa opinião na web é o que legitima esse público cada vez mais ativo na mídia. Interatividade ou participação? Qual o limite dessa interferência, se é que ela ocorre em determinados casos? As respostas a tais questionamentos abrangem implicaçōes de caráter técnico, social e cultural que demandam atenção por terem um papel definidor na constituição do entendimento do processo de convergência.

Pavlik (2008) cita uma pesquisa de John Carey sobre o uso de laptops paralelo ao uso da televisão, porém aponta algumas diferenças

8 A diferenciação entre interatividade e participação apresentada por Jenkins (2008) mostra a recorrente incidência de equívocos quanto ao uso dos termos interatividade/interativo(a). 
que soam interessantes no que se refere à materialidade dos meios. O autor destaca que a televisão não é móvel que nem o laptop e talvez não seja capaz de armazenar ou de disponibilizar todos os jogos de um time de futebol, por exemplo, como no caso da web, o que hoje já é algo questionável, em função dos canais pay-per-view. Um outro apontamento que Pavlik (2008) faz é de que o laptop é um dispositivo privado, ao contrário da televisão, que pode ser compartilhada com outras pessoas. No entanto, o autor não percebe o fato de que o telespectador pode acompanhar o jogo em canais coletivos, ou então interagindo com outros telespectadores, no caso, usuários de sites, e interagir com essas pessoas nessas páginas pelas quais acompanha os jogos, o que, dessa forma, tornaria, não o computador, mas o site, ou o ambiente no qual ele acompanha o jogo, em um espaço coletivo, acessado através do laptop.

Novamente o questionamento deve ser realizado com relação à interatividade e à participação no contexto da convergência. Percebe-se hoje um cenário múltiplo, complexificado pela diversidade de dispositivos tecnológicos e pelas possibilidades de manifestação oferecidas aos indivíduos através dessas materialidades que passam a ser apropriadas para os mais diversos usos. Apropriações e desvios complexificam a configuração midiática a partir de um movimento dialético entre a técnica, a cultura e a sociabilidade, borrando os limites entre interatividade e participação nos espaços on-line e off-line.

\section{Considerações finais}

Este paper resulta de uma tese de doutorado ainda em construção e, dessa forma, realiza um recorte no trabalho em andamento, discorrendo sobre uma das categorias que vêm sendo estudadas como constituintes do conceito de convergência midiática, a interatividade. Optou-se como estratégia tensionar a participação e a interatividade no contexto da convergência midiática com o objetivo de apontar que 
existem diferenças entre as duas características e que essas diferenças precisam ser pensadas não só em termos técnicos para a reflexão teórica sobre o processo de convergência, mas também em termos sociais e culturais.

Inicialmente, o texto direcionou seu foco para o conceito de convergência, buscando expor o entendimento tomado como base e motivado pela necessidade de superação do caráter tecnicista adotado por alguns autores na definição do fenômeno. Buscou-se explorar o tema da convergência abordando os três níveis propostos, técnico, social e cultural, passando por questôes referentes às materialidades dos suportes e dos meios e à apropriação realizada pelos indivíduos nos estabelecimentos dos processos comunicacionais e no consumo de produtos midiáticos. Em um segundo momento, o trabalho buscou enquadrar o conflito entre interatividade e participação como elementos constituintes do fenômeno, apontando situações em que os limites entre as duas características se tornam tênues e identificando como questôes comportamentais, que, além de maneiras técnicas, interferem, social e culturalmente, na definição do processo de convergência midiática.

Incitar a discussão e criar questionamentos que motivem o avanço teórico são as preocupações de origem desse trabalho, além dos objetivos inicialmente propostos. Dessa forma, sem a pretensão de esgotar o tema, as observações aqui expostas visam realizar essa contribuição ao campo.

\section{Referências}

CARDOSO, Gustavo. A mídia na sociedade em rede. Rio de Janeiro: FGV Editora, 2007.

CASTELLS, Manuel. A Galáxia da Internet. Rio de Janeiro: Editora Jorge Zahar. 2003. 
CHAGAS, Polyana Amorim. Um olho na TV e outro no computador: repercussão de produtos televisivos no Twitter. Revista Científica do Departamento de Comunicação Social daUniversidade Federal do Maranhão, São Luis, v. 19, n. 7, jan.- dez. 2010.

DIZARD JR., Wilson. A Nova Mídia. Jorge Zahar Editor. Rio de Janeiro, 2000.

FACCION, Debora. Processos de interação na cultura da convergência., In: Encontro dos Grupos de Pesquisas em Comunicação, 10. 2010, Caxias do Sul. Anais... Caxias do Sul: Intercom 2010. Disponível em: < http://www.intercom.org. br/papers/nacionais/2010/resumos/R5-1829-1.pdf. > Acesso em: 18 jul. 2011.

FELINTO, Erick. Em busca do tempo perdido. O sequestro da história na cibercultura e os desafios da teoria da mídia. MATRIZes, São Paulo, v. 4, n. 2, 2011. Disponível em: <http://www.matrizes.usp.br/ojs/index.php/matrizes/article/ view/138/pdf_214>. Acesso em: 8 ago. 2011

FRAGOSO, Suely. Reflexões sobre a convergência midiática. Líbero. Ano VIII, n. 15/16, 2005, online. Disponível em: <http:/geminisufscar.files.wordpress. com/2009/05/reflexoes_convergencia.pdf>. Acesso em: 19 jul. 2011

GRANT, August E.; WILKINSON, Jeffrey S. (Editors). Understanding Media Convergence: the state of the field. New York: Oxford University Press, 2009.

JENKINS, Henry. Cultura da Convergência. São Paulo: Editora Aleph, 2008.

JENKINS, Henry. O que aconteceu antes do YouTube? In: BURGESS, Jean; GREEN, Joshua. YouTube e a revolução digital: como o maior fenômeno da cultura participativa está transformando a mídia e a sociedade. São Paulo: Editora Aleph, 2009.

JENSEN, Klaus Bruhn. Media Convergence: the three degrees of network, mass, and interpersonal communication. New York: Routledge, 2010.

EMOS, André. Cibercultura: tecnologia e vida social na cultura contemporânea. Porto Alegre: Sulina, 2002.

LÉVY, Pierre. As tecnologias da inteligência: o futuro do pensamento na era da informática. São Paulo: Editora 34, 1993.

MACHADO, Arlindo. A televisão levada a sério. São Paulo: Editora Senac, 2003.

MURRAY, Janet H. Hamlet no holodeck: o futuro da narrativa no ciberespaço. São Paulo: Itaú Cultural: Unesp, 2003. 
MCLUHAN, Marshall. Os meios de comunicação como extensões do homem. São Paulo: Editora Cultrix, 1964.

NEGROPONTE, Nicholas. A vida digital. São Paulo: Companhia das Letras. 1995.

PAVLIK, John. Media in the digital age. New York: Columbia University Press. 2008.

PELLANDA, Eduardo Campos. Convergência de mídias potencializada pela mobilidade e um novo processo de pensamento. In: CONGRESSO BRASILEIRO DE CIÊNCIAS DA COMUNCAÇÃO, 23., 2003, Belo Horizonte. Anais...Belo Horizonte: Intercom, 2003.

POOL, Ithiel de Sola. Tecnologías sin fronteras de las telecomunicaciones en la época de la globalización. México, D.F.: Fondo de Cultura Económica, 1990. PRIMO, Alex. Interação mediada por computador: comunicação, cibercultura, cognição. Porto Alegre: Sulina, 2007.

THOMPSON, J.B. A mídia e a modernidade: uma teoria social da mídia. Rio de Janeiro: Editora Vozes, 1998.

SALAVERRÍA, Ramón; AVILÉS, José Alberto García. La convergencia tecnológica en los medios de comunicación: retos para el periodismo. Tripodos, n. 23, Barcelona, 2008. Disponível em: <http://www.tripodos.org/pdf/Salaverr\%C3\%ADa yGarc\%C3\%ADaAvil\%C3\%A9s.pdf84.pdf > Acesso em: 18 jul. 2011

SANTAELLA, Lucia. Da cultura das mídias à cibercultura: o advento do póshumanismo. In: Revista FAMECOS, Porto Alegre, v. xx, n. 22, dez. 2003. 